\title{
Analgesic effects of palonosetron in the intravenous propofol injection
}

\author{
Han-Bom Ryu and Su-Jin Kim \\ Department of Anesthesiology and Pain Medicine, Gyeongju Hospital, Dongguk University College of Medicine, Gyeongju, Korea
}

Background: Propofol is a good induction agent, but it has the disadvantage of causing pain on intravenous injection. The incidence of propofol-induced pain is approximately 70\%. Palonosetron is a novel second-generation 5-hydroxytryptamine type 3 (5-HT3) receptor antagonist. We presumed that palonosetron would be effective in reducing the occurrence of propofol-induced pain based on similar mechanisms to other 5-HT3 receptor antagonists.

Methods: Eighty patients were randomized to either Group N (0.9\% sodium chloride [normal saline] $2 \mathrm{ml}, \mathrm{n}=40)$ or Group P (palonosetron $0.075 \mathrm{mg}, 2 \mathrm{ml}, \mathrm{n}=40$ ). Patients were intravenously given a $2 \mathrm{ml}$ pretreatment solution, containing either palonosetron $0.075 \mathrm{mg}$ or normal saline. Following pretreatment with $2 \mathrm{ml}$ of palonosetron $0.075 \mathrm{mg}$ or normal saline, we manually occluded venous drainage midarm with the help of an assistant. One minute later, we released the occlusion of venous drainage. This was followed by a 5 -second propofol injection at $25 \%$ of the total calculated doses. Patients were then interviewed about whether or not they experienced propofol-induced pain.

Results: Overall, the incidence of propofol-induced pain was $60 \%$ in the normal saline group and $27.5 \%$ in the palonosetron group. No patients in the palonosetron group experienced severe pain. The incidence of propofol-induced pain was significantly lower in the palonosetron group compared to the normal saline group $(\mathrm{P}<0.01)$.

Conclusions: Following pretreatment with palonosetron, $72.5 \%$ of patients experienced a decrease in the occurrence of propofol-induced pain. (Korean J Anesthesiol 2014; 66: 99-104)

Key Words: Injections, Pain, Palonosetron, Propofol.

Received: May 9, 2013. Revised: 1st, June 11, 2013; 2nd, June 29, 2013; 3rd, July 21, 2013. Accepted: August 21, 2013.

Corresponding author: Su-Jin Kim, M.D., Ph.D., Department of Anesthesiology and Pain Medicine, Gyeongju Hospital, Dongguk University College of Medicine, 1090-1, Seokjang-dong, Gyeongju 780-350, Korea. Tel: 82-54-770-8317, Fax: 82-54-770-8500, E-mail: sujink100@hanmail.net (c) This is an open-access article distributed under the terms of the Creative Commons Attribution Non-Commercial License (http:// creativecommons.org/licenses/by-nc/3.0/), which permits unrestricted non-commercial use, distribution, and reproduction in any medium, provided the original work is properly cited. 


\section{Introduction}

With decreasing postoperative morbidity, the degree of patient satisfaction has begun to be of increasing interest throughout the perioperative period. One of the major causes of a lack of patient satisfaction is anesthetic-induced pain.

The incidence of propofol-induced pain is approximately $70 \%$, and it is the seventh most critical problem for American anesthesiologists in a clinical setting [1].

Propofol is one of the ideal anesthetics that cause minimal excitation, and it has the advantages of ensuring prompt induction of anesthesia and rapid emergence from anesthesia, as well as minimizing the occurrence of nausea and vomiting. It is therefore widely used for clinical purposes. Due to its side effect of causing pain, however, patient satisfaction is reduced with propofol, in spite of the agent's several advantages. To date, little is known about the mechanisms by which propofol provokes the pain. However, it has been reported to directly irritate the skin, mucous membranes, and venous intima, and thereby to stimulate nociceptors and free nerve endings [2].

Palonosetron, a substance used in the current study, is one of the 5-hydroxytryptamine type 3 (5-HT3) receptor antagonists that are commonly used as antiemetics. 5-HT3 receptor antagonists bind to $\mu$-receptors, thus acting as agonists. In addition, peripheral 5-HT3 receptors are involved in the nociceptive pathway, and this leads to the drugs' analgesic effect [3].

As it is a novel second-generation 5-HT3 receptor antagonist, the local anesthetic effect of palonosetron has not yet been described in the literature. We speculated, however, that palonosetron can be effectively used for the prevention of pain on propofol injection based on the reports of 5-HT3 receptor antagonists binding to $\mu$-receptors and thereby acting as agonists.

\section{Materials and Methods}

We conducted this study to compare the treatment effects of drugs acting on propofol-induced pain. We performed the experiment according to the following methods.

Inclusion criteria included patients who were scheduled to undergo elective surgery under general anesthesia, patients classified as American Society of Anesthesiologists (ASA) Physical status (PS) I and II, and patients aged between 15 and 65 years.
Based on these criteria, we enrolled 80 adults, both men and women, in the current study. The study was approved by the Institutional Review Board of our medical institution. Patients and their caregivers were fully informed of the study objectives and methods and submitted written informed consent.

Exclusion criteria include an inability to verbally express the severity of pain; the suspected presence of abnormalities of the heart, lungs, liver, and peripheral blood vessels; infection of the arm; and neurological deficits.

Our patients were randomized into two groups using block randomization: Group $\mathrm{N}$ (normal saline $2 \mathrm{ml}, \mathrm{n}=40$ ) and Group P (palonosetron $0.075 \mathrm{mg}, 2 \mathrm{ml}, \mathrm{n}=40$ ).

No patients were given analgesics within 12 hours preoperatively. In addition, no drugs were administered to any patients prior to the induction of anesthesia.

On arrival in the operating room, patients had a 20 gauge venous catheter placed in the dorsum of the hand.

Vital signs were measured by placing an electrocardiogram, a non-invasive BP monitor, and a pulse oximeter on the patients, followed by a 10 minute stabilization period. Then, we informed the patients of the severity of the pain induced by propofol (Provive $^{\mathrm{TM}}$, Myungmoon Pharm. Co. Ltd., Seoul, Korea).

Patients were intravenously given a $2 \mathrm{ml}$ pretreatment solution, containing either palonosetron $0.075 \mathrm{mg}$ or normal saline, after which the anesthesia was induced using propofol $2.0 \mathrm{mg} / \mathrm{kg}$. Pretreatment solutions were prepared by an anesthesiologist who was blinded to their constituents. Following 5 seconds pretreatment with $2 \mathrm{ml}$ of palonosetron $0.075 \mathrm{mg}$ or normal saline, we manually occluded venous drainage midarm with the help of an assistant. One minute later, we released the occlusion of venous drainage [4]. This was followed by a 5 second propofol injection at $25 \%$ of the total calculated doses. Patients were then interviewed about whether or not they experienced propofolinduced pain [2].

To evaluate the severity of propofol-induced pain, we used a 4-point scale with the following values: None (no discomfort at the site of injection, 0 points), Mild (the presence of pain without behavioral changes, 1 point), Moderate (subjective symptoms or the concurrent presence of behavioral changes, 2 points), and Severe (severe pain or the concurrent presence of such responses as making a face, hunching arms, or shedding tears, 3 points) $[2,5]$ (Table 1 ).

Table 1. Assessment of Pain

\begin{tabular}{cll}
\hline Score & Degree of pain & Response \\
\hline 0 & None & Negative response to questioning. \\
1 & Mild & Pain reported in response to questioning only, without any behavioral signs. \\
2 & Moderate & Pain reported in response to questioning and accompanied by a behavioral sign, or pain reported spontaneously without \\
3 & Severe & questioning. \\
\hline
\end{tabular}


The calculated sample size determined that 31 patients per group were required with an $\alpha$ value of 0.05 and a power value of $80 \%$ to confirm the efficacy with at least a $30 \%$ difference between the normal saline group and palonosetron group with respect to propofol-induced pain, and that 40 patients per group were required with an $\alpha$ value of 0.01 . In order to obtain greater significance, the final sample size was determined to be 40 patients per group.

Statistical analyses were performed using SPSS version 19.0 for Windows (SPSS Inc., Chicago, IL, USA). The chi-square test was used to compare gender, ASA PS, and propofol-induced pain between the two groups. Comparison of age, height, and weight between the two groups was obtained by Student's t-test. The results were expressed as number or means \pm standard deviation $(\mathrm{SD})$. A P value $<0.05$ was considered to be statistically significant.

\section{Results}

A total of 80 patients were enrolled in the study, 40 of whom were randomly assigned to each of the two groups. The age, weight, and ASA PS of the patients are summarized in Table 2. There were no significant differences in these baseline characteristics between the two groups. Table 3 represents the number of patients of both groups who presented with pain or discomfort. Sixteen patients in the normal saline group and 29 patients in

Table 2. Demographic Data

\begin{tabular}{lccc}
\hline & $\begin{array}{c}\text { Group N } \\
(\mathrm{n}=40)\end{array}$ & $\begin{array}{c}\text { Group P } \\
(\mathrm{n}=40)\end{array}$ & $\begin{array}{c}\text { P value } \\
\text { (two-tailed) }\end{array}$ \\
\hline Age $(\mathrm{yr})$ & $43.83 \pm 11.32$ & $43.13 \pm 10.18$ & 0.772 \\
Height $(\mathrm{cm})$ & $165.28 \pm 8.07$ & $165.38 \pm 9.16$ & 0.959 \\
Weight $(\mathrm{kg})$ & $62.30 \pm 9.44$ & $65.50 \pm 10.40$ & 0.153 \\
Gender $(\mathrm{M} / \mathrm{F})$ & $20 / 20$ & $20 / 20$ & \\
ASA physical status (I/II) & $33 / 7$ & $33 / 7$ & \\
\hline
\end{tabular}

Values are number of patients or mean \pm SD. Group N: received normal saline, Group P: received palonosetron. The measured values for patients' age, height, and weight showed no significant differences between the two groups.

Table 3. Distribution of Pain Scores by Groups

\begin{tabular}{lcc}
\hline & Group N $(\mathrm{n}=40)$ & Group P $(\mathrm{n}=40)$ \\
\hline Mild to severe pain & $24(60.0 \%)$ & $11(27.5 \%)^{*}$ \\
Moderate to severe pain & $14(35.0 \%)$ & $1(2.5 \%)^{*}$ \\
0: No pain & $16(40.0 \%)$ & $29(72.5 \%)$ \\
1: Mild pain & $10(25.0 \%)$ & $10(25.0 \%)$ \\
2: Moderate pain & $10(25.0 \%)$ & $1(2.5 \%)$ \\
3: Severe pain & $4(10.0 \%)$ & $0(0.0 \%)$ \\
\hline
\end{tabular}

Values are number of patients (\%). Group N: received normal saline, Group P: received palonosetron. $* \mathrm{P}<0.01$ is compared with Group N. the palonosetron group experienced no pain (0 points). There were significantly more patients without pain or discomfort in the palonosetron group than in the normal saline group during injection of propofol. However, there was no statistically significant difference in the number of patients who experienced mild pain ( 1 point) between the normal saline (10 patients) and palonosetron (10 patients) groups. The numbers of patients who experienced moderate and severe pain ( 2 and 3 points) were 10 and 4 in the normal saline group, and 1 and 0 in the palonosetron group, respectively. Consequently, patients with moderate to severe pain were significantly fewer in the palonosetron group than in the normal saline group.

Overall, the incidence of propofol-induced pain was $60 \%$ in the normal saline group and $27.5 \%$ in the palonosetron group. In addition, 14 patients in the normal saline group and 1 patient in the palonosetron group presented with moderate-to-severe pain. However, there were no patients in the palonosetron group who presented with severe pain.

The incidence of propofol-induced pain was significantly lower in the palonosetron group as compared to the normal saline group $(\mathrm{P}<0.01)$.

\section{Discussion}

Used in the current experimental study, palonosetron is a novel 5-HT3 receptor antagonist. As compared with the older first-generation 5-HT3 receptor antagonists, it is more effective in preventing the occurrence of acute (0-24 hr) and delayed (24-120 hr) emesis [6,7].

Of various types of 5-HT3 receptor antagonists, palonosetron uniquely triggers the occurrence of 5-HT3 receptor internalization, and it also causes a prolonged inhibition of the receptor function.

The improved clinical efficacy of palonosetron is partly based on its strong binding affinity and long half-life [8].

5 -HT3 receptors are located in the nerve terminals and sensory nerve endings of neurons releasing pain mediators such as substance P. Therefore, there has been an increased interest in the clinical use of 5-HT3 receptor antagonists for the management of diseases causing chronic pain, such as fibromyalgia and peripheral neuropathy. These treatment effects are associated with substance P-mediated inflammation and hyperalgesia [9].

We speculated that palonosetron would be effective in reducing the occurrence of pain based on similar mechanisms to other 5-HT3 receptor antagonists.

In our hospital, palonosetron is used for preventing intravenous patient-controlled analgesia induced nausea/vomiting and postoperative nausea/vomiting (PONV). It is presumed that if palonosetron, like other 5-HT3 receptor antagonists, has an effect on reducing propofol-induced pain, the use of palonose- 
tron before the administration of propofol will be effective in preventing both PONV and propofol-induced pain. Although propofol is a widely used venous anesthetic, the pain it induces is not well tolerated by patients.

Propofol microemulsion is composed of an inner phase and an outer phase; the former is a mixture of pure soya oil, soya oil, and safflower oil, or it comprises a mixture of soya oil (long chain triglyceride) and medium chain triglyceride, and the latter is a water soluble component that directly irritates the internal wall of the blood vessels and thereby produces pain. It is the outer phase that is associated with the occurrence of propofolinduced pain [10].

Little is known about the mechanisms by which propofol induces the pain. These mechanisms, however, have been reported to originate from such phenomena as endothelial irritation, the difference in osmolarity, non-physiological $\mathrm{pH}$, and the activation of pain mediators [11].

The first factor causing pain is the immediate stimulation of nociceptors and free nerve endings, and it is mainly associated with the amount of free drug that is contained in the aqueous phase of the emulsion [10,11].

The delayed pain occurring within half a minute is due to the interaction between nociceptors and free nerve endings. It is promoted by local vasodilation and hyperpermeability with the mediation of such neurotransmitters as bradykinin and prostaglandin E2 [12].

Injection-related discomfort occurs within 10-20 seconds following the injection, and it is persistently present only during the injection. Its symptoms include not only sharp pain but also aching and burning sensations.

There are several methods to reduce the pain caused by propofol injection, including increasing the infusion rate; adding opioids, aspirin, and lidocaine; cooling or diluting the propofol; and performing pretreatment with lidocaine, ephedrine, ondansetron, metoclopramide, nafamostat mesilate, thiopental, or ketamine $[2,5,13]$.

The addition of lidocaine or its pretreatment prior to propofol injection, in particular, is frequently done. Lidocaine blocks sodium channels and thereby acts as a local anesthetic. Its kinin cascade-stabilizing effect suppresses the release of pain mediators, thus reducing the occurrence of propofol-induced pain.

None of these methods, however, is effective in completely preventing the occurrence of pain; depending on the method of delivering propofol, approximately $13-44 \%$ of patients generally complain of pain $[14,15]$.

5-HT3 receptors are located in the chemoreceptor trigger zone of the area postrema of the central nervous system. Peripherally, they are located in the vagal nerve endings [16].

Peripheral 5-HT3 receptors are involved in the nociceptive pathway. 5-HT3 receptor antagonists can therefore be used as a local anesthetic based on their effect in blocking sodium channels. Experimental studies with animals have shown that intrathecal injection of 5-HT3 receptor antagonists reduced the occurrence of mechanical allodynia $[17,18]$.

5-HT3 receptor antagonists were first reported to be effective in treating chemotherapy-induced nausea and vomiting. These treatment effects are based on radiotherapy or have been used to manage surgery-induced nausea and vomiting $[19,20]$.

It has also been disclosed that 5-HT3 receptor antagonists bind to opioid $\mu$-receptors and thereby act as agonists. This leads to their analgesic effect [3].

Animal experimental studies using rats have shown that the local anesthetic effects of ondansetron were more than 15 times higher than those of lidocaine. It has also been disclosed that skin injection of ondansetron led to numbness $[3,17,18]$.

5 -HT3 receptor antagonists act as $\mu$-opioid agonists that block sodium channels. It can therefore be hypothesized that they may be effective in reducing the occurrence of propofolinduced pain.

There are currently seven types of 5-HT3 receptor antagonists (ondansetron, granisetron, dolasetron, palonosetron, alosetron, tropisetron and ramosetron) that are commercially available [21].

Ambesh et al. [2] reported that the occurrence of propofolinduced vascular pain was reduced to $25 \%$ following pretreatment with ondansetron $4 \mathrm{mg}$. In another study, Kang et al. [22] reported that it was reduced to $33.3 \%$. Furthermore, Lee et al. [23] also noted that pretreatment with ondansetron $4 \mathrm{mg}$ was effective in preventing the occurrence of propofol-induced vascular pain.

According to Ahmed et al. [24], following pretreatment with granisetron $1 \mathrm{mg}$, $60 \%$ of patients in the normal saline group complained of pain, but only $15 \%$ of patients in the granisetron group did. Granisetron is a more refined 5-HT3 receptor antagonist.

Additionally, in a study conducted by Lee et al. [25], following pretreatment with ramosetron $0.3 \mathrm{mg}, 96 \%$ of patients in the normal saline group complained of pain, but only $60 \%$ of patients in the ramosetron group did.

Our results showed that $60 \%$ of patients in the normal saline group complained of pain, while only $27.5 \%$ of patients in the palonosetron group did.

These results might originate from peripheral local anesthetic action, nociceptive pathway impairment, and similar mechanisms to those of other types of 5-HT3 receptor antagonists.

Although palonosetron was not effective in preventing the occurrence of pain in all of the current study patients, it was effective in $72.5 \%$ of those patients. This is quite a significant response when compared with previously reported results for other 5-HT3 receptor antagonists [2,22-25].

In the current study, pretreatment with palonosetron was effective in reducing the occurrence of propofol-induced pain. 
Moreover, of various types of 5-HT3 receptor antagonists, palonosetron is uniquely effective for the management of both acute and delayed emesis. Stoltz et al. [26] demonstrated that palonosetron undergoes a slow elimination phase which results in a long half-life of approximately 40 hours, in contrast to ondansetron, which has a half-life of approximately 5 hours. In addition, Park and Cho [27] reported that the incidence of PONV was significantly lower in the palonosetron $0.075 \mathrm{mg}$ group compared with the ondansetron $8 \mathrm{mg}$ group during the first 24 hours after anesthesia. Therefore, pretreatment with palonosetron is an effective method of reducing the occurrence of propofol-induced pain and has the advantage of preventing PONV without the additional administration of other drugs.

To summarize, we examined whether an intravenous injection of palonosetron $0.075 \mathrm{mg}$ would be effective in reducing the occurrence of propofol-induced pain. We compared the proportion of patients who complained of pain between two groups: the normal saline group and the palonosetron group. Our results showed that patients in the palonosetron group complained of pain to a lesser extent.

\section{References}

1. Macario A, Weinger M, Truong P, Lee M. Which clinical anesthesia outcomes are both common and important to avoid? The perspective of a panel of expert anesthesiologists. Anesth Analg 1999; 88: 1085-91.

2. Ambesh SP, Dubey PK, Sinha PK. Ondansetron pretreatment to alleviate pain on propofol injection: a randomized, controlled, doubleblinded study. Anesth Analg 1999; 89: 197-9.

3. Gregory RE, Ettinger DS. 5-HT3 receptor antagonists for the prevention of chemotherapy-induced nausea and vomiting. A comparison of their pharmacology and clinical efficacy. Drugs 1998; 55: 173-89.

4. Massad IM, Abu-Ali HM, Abu-Halaweh SA, Badran IZ. Venous occlusion with lidocaine for preventing propofol induced pain. A prospective double-blind randomized study. Saudi Med J 2006; 27: 997-1000.

5. McCrirrick A, Hunter S. Pain on injection of propofol: the effect of injectate temperature. Anaesthesia 1990; 45: 443-4.

6. Aapro MS, Grunberg SM, Manikhas GM, Olivares G, Suarez T, Tjulandin SA, et al. A phase III, double-blind, randomized trial of palonosetron compared with ondansetron in preventing chemotherapy-induced nausea and vomiting following highly emetogenic chemotherapy. Ann Oncol 2006; 17: 1441-9.

7. Eisenberg P, Figueroa-Vadillo J, Zamora R, Charu V, Hajdenberg J, Cartmell A, et al. Improved prevention of moderately emetogenic chemotherapy-induced nausea and vomiting with palonosetron, a pharmacologically novel 5-HT3 receptor antagonist: results of a phase III, single dose trial versus dolasetron. Cancer 2003; 98: 2473-82.

8. Stoltz R, Cyong JC, Shah A, Parisi S. Pharmacokinetic and safety evaluation of palonosetron, 5-hydroxytryptamine-3 receptor antagonist, in U.S. and Japanese healthy subjects. J Clin Pharmacol 2004; 44: 520-31.

9. Faerber L, Drechsler S, Ladenburger S, Gschaidmeier H, Fischer W. The neuronal 5-HT3 receptor network after 20 years of researchevolving concepts in management of pain and inflammation. Eur J Pharmacol 2007; 560: 1-8.

10. Doenicke AW, Roizen MF, Rau J, Kellermann W, Babl J. Reducing pain during propofol injection: the role of the solvent. Anesth Analg 1996; 82: 472-4.

11. Tan CH, Onsiong MK. Pain on injection of propofol. Anaesthesia 1998; 53: 468-76.

12. Nishiyama T. How to decrease pain at rapid injection of propofol: effectiveness of flurbiprofen. J Anesth 2005; 19: 273-6.

13. Picard P, Tramèr MR. Prevention of pain on injection with propofol: a quantitative systematic review. Anesth Analg 2000; 90: 963-9.

14. Nathanson MH, Gajraj NM, Russell JA. Prevention of pain on injection of propofol: a comparison of lidocaine with alfentanil. Anesth Analg 1996; 82: 469-71.

15. Walker BJ, Neal JM, Mulroy MF, Humsi JA, Bittner RC, McDonald SB. Lidocaine pretreatment with tourniquet versus lidocaine-propofol admixture for attenuating propofol injection pain: a randomized controlled trial. Reg Anesth Pain Med 2011; 36: 41-5.

16. Watcha MF, White PF. Postoperative nausea and vomiting: Its etiology, treatment, and prevention. Anesthesiology 1992; $77: 162-84$.

17. Ye JH, Mui WC, Ren J, Hunt TE, Wu WH, Zbuzek VK. Ondansetron exhibits the properties of a local anesthetic. Anesth Analg 1997; 85: 1116-21.

18. Ali Z, Wu G, Kozlov A, Barasi S. The role of 5-HT3 in nociceptive processing in the rat spinal cord: results from behavioral and electrophysiological studies. Neurosci Lett 1996; 208: 203-7.

19. Hesketh PJ. New treatment options for chemotherapy-induced nausea and vomiting. Support Care Cancer 2004; 12: 550-4.

20. Kazemi-Kjellberg F, Henzi I, Tramèr MR. Treatment of established postoperative nausea and vomiting: a quantitative systematic review. BMC Anesthesiol 2001; 1: 2.

21. Machu TK. Therapeutics of 5-HT3 receptor antagonists: current uses and future directions. Pharmacol Ther 2011; 130: 338-47.

22. Kang WJ, Hong SK, Kim KS. Effect of ondansetron and lidocaine on vascular pain associated with intravenous propofol injection. Korean J Anesthesiol 2004; 46: 393-6.

23. Lee HS, Song JH, Kim TJ, Han JU, Lim HK, Shin H, et al. Comparison of dexamethasone and ondansetron for the prevention of nausea and vomiting using intravenous patient-controlled analgesia after gynecologic surgery. Korean J Anesthesiol 2004; 47: 726-31. 
24. Ahmed A, Sengupta S, Das T, Rudra A, Iqbal A. Pre-treatment with intravenous granisetron to alleviate pain on propofol injection: A double-blind, randomized, controlled trial. Indian J Anaesth 2012; 56: 135-8.

25. Lee HY, Kim SH, So KY. Prevention of microemulsion propofol injection pain: a comparison of a combination of lidocaine and ramosetron with lidocaine or ramosetron alone. Korean J Anesthesiol 2011; 61: 30-4.

26. Stoltz R, Parisi S, Shah A, Macciocchi A. Pharmacokinetics, metabolism and excretion of intravenous [14C]-palonosetron in healthy human volunteers. Biopharm Drug Dispos 2004; 25: 329-37.

27. Park SK, Cho EJ. A randomized, double-blind trial of palonosetron compared with ondansetron in preventing postoperative nausea and vomiting after gynaecological laparoscopic surgery. J Int Med Res 2011; 39: 399-407. 